\title{
Pulmonary ultrasound in the evaluation of the alveolar-interstitial syndrome in the post-operative period of aortic valve surgery and pulmonary hypertension
}

\author{
El ultrasonido pulmonar en la evaluación del síndrome alveolo-intersticial en el \\ postoperatorio de cirugía valvular aórtica e hipertensión pulmonar
}

\section{Luis E. Santos-Martínez",2*, Jessica Garduño-López¹, Gastón Mendoza-Copa¹, Edgar García-Cruz", Efren Melano-Carranza', Miguel Á. Hernández-Márquez', and Francisco M. Baranda-Tovar ${ }^{1}$}

${ }^{1}$ Department of Cardiovascular Postsurgical Intensive Care, Secretaría de Salubridad y Asistencia, Instituto Nacional de Cardiología Ignacio Chávez; ${ }^{2}$ Department of Pulmonary Hypertension and Right Heart, Instituto Mexicano del Seguro Social, Centro Médico Nacional Siglo XXI, High Specialty Medical Unit Cardiology Hospital, Mexico City, Mexico

Pleuropulmonary assessment at intensive care units $(\mathrm{ICU})^{1-4}$ is traditionally performed with plain chest radiograph (X-ray) in anteroposterior view. Its limitation has been low diagnostic accuracy in lung disease. Chest axial tomography solved this problem, but its drawback was radiation and mobilizing the patient outside the ICU is required ${ }^{1-4}$.

Lung ultrasound (LUS) has complemented this assessment ${ }^{1}$. Its usefulness at the ICU is focused on the diagnosis of pulmonary consolidation syndromes, pleural effusion, pulmonary edema (PE), and pneumothorax ${ }^{1-4}$; however, in PE assessment, it appears not to discriminate between cardiogenic ${ }^{3}$ and non-cardiogenic origin ${ }^{5}$, which is why in the field of ultrasonography it has been called alveolar-interstitial syndrome.

In the early post-operative period of cardiac surgery, there is the possibility that the patient experiences cardiogenic ${ }^{6}$ and/or non-cardiogenic PE of various caus$\mathrm{es}^{5}$, such as pulmonary infection or transfusion-related acute lung injury (TRALI) ${ }^{7}$.
We present the clinical evolution, imaging, hemodynamics, and laboratory tests of a patient in the post-operative period of an aortic valve replacement procedure with pulmonary hypertension (PH), complicated with $\mathrm{PE}$ (alveolar-interstitial syndrome). The interest of the present communication is to emphasize the value of LUS imaging in PE (alveolar-interstitial syndrome).

Seventy-one-year-old male patient, with a prior history of systemic arterial hypertension on treatment with losartan/hydrochlorothiazide since 2008. Intense chronic alcohol consumption, with more than $60 \mathrm{~g} /$ day intake for more than 20 years. His condition started in 2017 with progressive severe-to-moderate effort dyspnea that limited his daily activities. He was assessed in a hospital setting and treated for heart failure. In August 2018, calcified aortic valve with commissural fusion was documented by echocardiography, which caused a double lesion, severe stenosis, and moderate insufficiency with a valve area of $0.7 \mathrm{~cm}^{2}$, mean gradient of $78.6 \mathrm{mmHg}$, maximum velocity $6.5 \mathrm{~m} / \mathrm{s}$, pulmonary

\section{Correspondence:}

*Luis E. Santos-Martínez

Avenida Cuauhtémoc, 330

Date of reception: 24-02-2019

Date of acceptance: 13-03-2019

E-mail: sanlui@ cardiologia.org.mx 2604-7063/@ 2019 Instituto Nacional de Cardiología Ignacio Chávez. Published by Permanyer. This is an open access article under the CC BY-NC-ND license (http://creativecommons.org/licenses/by-nc-nd/4.0/). 


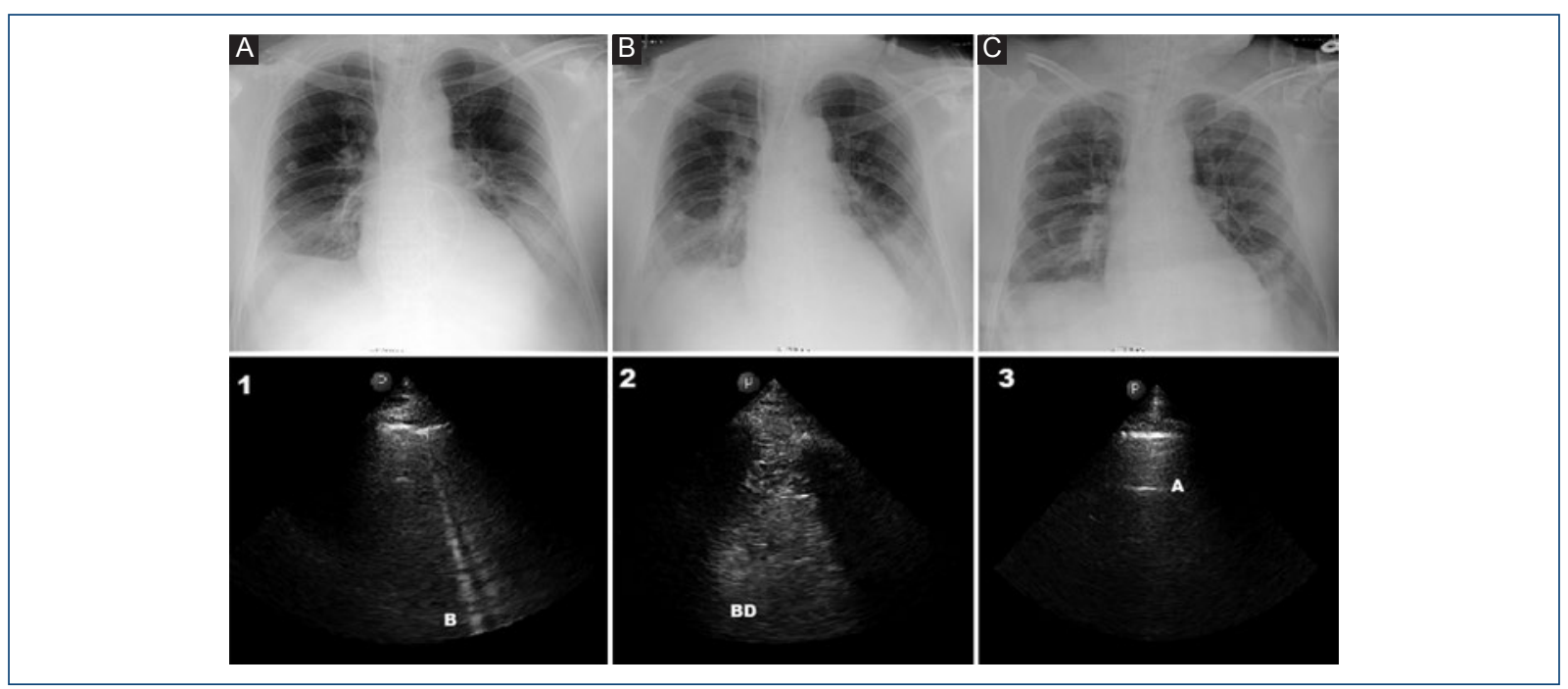

Figure 1. Chest X-ray and lung ultrasound correlation in the patient with alveolar-interstitial syndrome. Chest X-ray A: with portable equipment in anteroposterior view, which suggests the presence of interstitial occupation and obliteration of both costal and diaphragmatic angles. Pulmonary ultrasound 1: the presence of B-lines suggesting interstitial occupation (alveolar-interstitial syndrome). Chest X-ray B: the presence of bilateral consolidation and obliteration of both costal and diaphragmatic angles, with increased bronchovascular marking. Lung ultrasound 2: dynamic bronchogram evidence suggesting consolidation. Chest X-ray C: decrease of consolidation pattern and improvement in both costal and diaphragmatic angles. Lung ultrasound 3: dynamic bronchogram pattern decrease and appearance of A-lines, which suggests a normalized pattern on ultrasound.

artery systolic pressure of $77 \mathrm{mmHg}$, and left atrium dilation.

The patient underwent an aortic valve replacement procedure with Edwards \# 23 biological prosthesis and ascending aortic plication in our institution. Surgical time was $314 \mathrm{~min}$, anesthetic time $390 \mathrm{~min}$, cardiopulmonary bypass $105 \mathrm{~min}$, and aortic clamping $88 \mathrm{~min}$. The total bleeding was $1060 \mathrm{ml}$, with $962 \mathrm{ml}$ being recovered by cell saver. Two platelet apheresis and $3 \mathrm{IU}$ of cryoprecipitates were transfused, in addition to $1000 \mathrm{IU}$ of prothrombin complex and $30 \mathrm{mcg} / \mathrm{i} . \mathrm{v}$. desmopressin. At discharge from the operating room, bleeding was $180 \mathrm{ml}$ in $50 \mathrm{~min}$.

When in the ICU, the situation was complicated by more than usual bleeding $(420 \mathrm{ml} / \mathrm{h})$, with one unit of packed red blood cells and $30 \mathrm{mcg}$ of extra desmopressin being transfused, and surgical reexploration being required within the first $4 \mathrm{~h}$.

He developed low cardiac output syndrome (LCOS) (cardiac output $3.4 \mathrm{~L} / \mathrm{min}$, cardiac index $1.9 \mathrm{~L} / \mathrm{min} / \mathrm{m}^{2}$, pulmonary capillary pressure $7 \mathrm{mmHg}$, central venous pressure $10 \mathrm{mmHg}$, and systemic vascular resistance index $1.105 \mathrm{dynes} / \mathrm{m}^{2}$ ). A double vasopressor therapeutic scheme (norepinephrine and vasopressin) and a drug with inotropic activity (dobutamine) were necessary.
He also showed gas exchange deterioration and mechanical ventilation increased support ( $80 \%$ inspired oxygen fraction, positive end-expiratory pressure $18 \mathrm{mmHg}$, blood oxygen tension $51 \mathrm{mmHg}$, blood carbon dioxide tension $37 \mathrm{mmHg}$, and partial pressure arterial oxygen/fraction of inspired oxygen ratio 63.7), which is why adult respiratory distress syndrome (ARDS) was defined as the most likely cause or, according to its presentation on LUS, as alveolar-interstitial syndrome. Its behavior on chest X-ray and LUS is shown in figure 1; in addition, hemodynamic variables, gas exchange, laboratory tests, mechanical ventilation, and fluid balance are presented in table 1.

This patient, categorized as belonging to $\mathrm{PH}$ consensus Group II, underwent an aortic valve replacement surgical procedure ${ }^{8}$. $\mathrm{PH}$ decreased once the valve obstruction was removed.

In the immediate post-operative period, he developed LCOS and more than usual bleeding. He had cardiopulmonary deterioration, which in a > 70-year-old subject with a history of transfusions and lower airway infection was classified as ARDS.

In this context, there seems to be a clinical-diagnostic overlap in a patient at the post-operative period of cardiac surgery who developed LCOS and who presented 
Table 1. Post-operative behavior of hemodynamic variables, gas exchange, mechanical ventilation, fluid balance, and laboratory tests

\begin{tabular}{|c|c|c|c|}
\hline Variable & Day 1 & Day 2 & Day 3 \\
\hline $\begin{array}{l}\text { Hemodynamic } \\
\text { Cardiac index, } \mathrm{L} / \mathrm{min} / \mathrm{m}^{2} \\
\text { Cardiac output, } \mathrm{L} / \mathrm{min} \\
\text { Central venous pressure, } \mathrm{mmHg} \\
\text { Pulmonary wedge pressure, } \mathrm{mmHg} \\
\text { Pulmonary artery mean pressure, } \mathrm{mmHg} \\
\text { Systemic vascular resistance index, dynes } / \mathrm{m}^{2}\end{array}$ & $\begin{array}{c}2.6 \\
4.7 \\
9 \\
11 \\
20 \\
1944\end{array}$ & $\begin{array}{c}2.8 \\
5.1 \\
6 \\
7 \\
18 \\
1696\end{array}$ & $\begin{array}{c}2.8 \\
5.2 \\
11 \\
13 \\
22 \\
2086\end{array}$ \\
\hline $\begin{array}{l}\text { Arterial and venous gas exchange } \\
\text { Arterial hydrogen potential }(\mathrm{pH}) \\
\text { Arterial oxygen tension, } \mathrm{mmHg} \\
\text { Arterial carbon dioxide tension, } \mathrm{mmHg} \\
\text { Serum bicarbonate, mmol/L } \\
\text { Base excess, mmol/L } \\
\text { Arterial oxygen saturation, } \% \\
\text { Serum lactate, mmol/L } \\
\text { Central venous hydrogen potential }(\mathrm{pH}) \\
\text { Central venous carbon dioxide tension, } \mathrm{mmHg} \\
\text { Central venous oxygen saturation, \% }\end{array}$ & $\begin{array}{c}7.42 \\
51 \\
37 \\
24 \\
-0.5 \\
88.7 \\
3.4 \\
7.28 \\
54 \\
56.8\end{array}$ & $\begin{array}{c}7.48 \\
69 \\
38 \\
27 \\
3 \\
95 \\
2 \\
7.44 \\
39 \\
68.9\end{array}$ & $\begin{array}{c}7.51 \\
66 \\
36 \\
29 \\
6.4 \\
95.3 \\
1.6 \\
7.5 \\
30.8 \\
55.7\end{array}$ \\
\hline $\begin{array}{l}\text { Mechanical ventilation } \\
\text { Positive end-expiratory pressure, } \mathrm{cmH}_{2} \mathrm{O} \\
\text { Fraction of inspired oxygen, } \% \\
\text { Static distensibility } \\
\text { Partial arterial oxygen pressure/fraction of inspired oxygen }\end{array}$ & $\begin{array}{c}8 \\
85 \\
49 \\
60\end{array}$ & $\begin{array}{c}10 \\
45 \\
70 \\
153\end{array}$ & $\begin{array}{c}9 \\
40 \\
69 \\
165\end{array}$ \\
\hline $\begin{array}{l}\text { Laboratory tests } \\
\text { Hemoglobin, } \mathrm{mg} / \mathrm{dL} \\
\text { Leukocytes, } 10^{*} 3 / \mathrm{L} \\
\text { Glucose, } \mathrm{mg} / \mathrm{dL} \\
\text { Blood urea nitrogen (BUN), mg/dL } \\
\text { Serum creatinine, } \mathrm{mg} / \mathrm{dL} \\
\text { High sensitivity C-reactive protein, } \mathrm{mg} / \mathrm{dL} \\
\text { Fluid balance, } \mathrm{mL} \\
\text { Bronchial secretion culture }\end{array}$ & $\begin{array}{c}7.9 \\
17 \\
14.2 \\
157 \\
12 \\
1.4 \\
+4869\end{array}$ & $\begin{array}{c}8.8 \\
23 \\
21 \\
207 \\
38 \\
1.6 \\
61.32 \\
+5691 \\
\text { Gram-negative bacilli } \\
\text { Gram-positive cocci }\end{array}$ & $\begin{array}{c}8.3 \\
24.1 \\
20.8 \\
106 \\
42 \\
1.69 \\
42 \\
+4715 \\
\text { Citrobacter } \\
\text { Proteus } \\
\text { Enterobacter }\end{array}$ \\
\hline
\end{tabular}

with TRALI and lower respiratory infection, which led to alveolar-interstitial syndrome, which was supported by cytometry values and positive cultures, as it is shown in table 1 and figure 1.

LUS has become a highly useful diagnostic tool, since being able to obtain real-time images is non-invasive, and mobilizing the patient outside the ICU is not necessary.

Air and water contrast produces different acoustic impedance values, which causes reverberation that can be seen on the screen as vertical lines known as B-lines ${ }^{2}$. As the water content increases and alveolar air decreases, i.e., interlobular septum thickens and alveolar space is filled with fluid, it causes the appearance of multiple and diffuse B-lines ${ }^{2}$ : alveolar-interstitial syndrome. Diagnostic sensitivity has been reported to be $93.4 \%$ and specificity, $93 \%{ }^{9}$.

In cardiac surgery patients, the number of B-lines was found to be related to the amount of extravascular lung water $(E V L W)^{10}$. In acute heart failure, the amount of EVLW has been associated with mortality ${ }^{10}$.

In other fields, LUS usefulness could be of support in emergency units for dyspnea differential diagnosis and would help distinguish cardiac from pulmonary causes, as in chronic obstructive pulmonary disease exacerbation and, moreover, in acute heart failure treatment and hemodialysis response in patients with $\mathrm{PE}^{2-4}$.

As for pneumonia, LUS was shown to be reliable in a study with 100 ICU patients with suspected pneumonia who underwent LUS, chest X-ray, and computed tomography. Sensibility (S), specificity (Sp), positive predictive value (PPV), negative predictive value (NPV), as well as diagnostic accuracy (DxA), respectively, for LUS versus chest X-ray were as follows: $S 97.5$ versus 77.5, Sp 75 versus 60, VPP 94 versus 88.6, VPN 88.2 versus 40 , and DxA 93 versus $74^{11}$. 
Two major limitations can be observed for LUS intervention in the subject at post-operative period of cardiac surgery. The first one is in the differential diagnosis between cardiogenic and non-cardiogenic PE since LUS will only show the presence of B-lines (alveolar-interstitial syndrome), and for differential diagnosis, it will also require hemodynamic evaluation (SwanGanz catheter), as noted in this clinical case. The other major limitations are inter- and intraobserver variability, which might occur with this diagnostic method ${ }^{2-4}$.

From the point of view of the doctor with a specialty in critical medicine, LUS is a useful tool for the diagnosis and monitoring of chest diseases in critically ill patients. In favor, it offers the possibility to be applied in real time, at the patient bedside, and free of the risks of radiation. Its limitations would be being highly operator dependent, presence of subcutaneous emphysema, chest compresses, or pleural calcifications ${ }^{11}$.

Finally, LUS is a useful tool that supports the diagnosis and follow-up of some cardiopulmonary entities that occur in a population of patients in the post-operative period of cardiovascular surgery.

\section{Funding}

None.

\section{Conflicts of interest}

None.

\section{Ethical disclosures}

Protection of people and animals. The authors declare that no experiments were performed on humans or animals for this study.

Confidentiality of data. The authors declare that they have followed the protocols of their work center on the publication of patient data.

Right to privacy and informed consent. The authors declare that no patient data appear in this article.

\section{References}

1. Shrestha GS, Weeratunga D, Baker K. Point of care lung ultrasound in critically ill patients. Rev Recent Clin Trials. 2018; 31;13(1):15-26.

2. Volpicelli G, Melniker LA, Cardinale L, Lamorte A, Frascisco MF. Lung ultrasound in diagnosing and monitoring pulmonary interstitial fluid. Radiol Med. 2013;118(2);196-205.

3. Cortellaro F, Ceriani E, Spinelli M, Campanella C, Bossi I, Coen D et al. Lung ultrasound for monitoring cardiogenic pulmonary edema. Intern Emerg Med. 2016;12(7):1011-7.

4. Gargani L. Lung ultrasound: a new tool for the cardiologist. Cardiovascular Ultrasound. 2011;9:6.

5. Rawal G, Yadav S, Kumar E. Acute respiratory distress syndrome: An update and review. J Transl Intern Med. 2018:6(2);74-7.

6. Reyes-Sánchez ME, Carrillo-Rojas JA, Hernández-Mercado MA, Amaro-Camacho JA, Herrera-Garza EH, López Pineda DM, et al. Síndrome de bajo gasto cardiaco post-cardiotomía. Arch Cardiol Mex. 2011;81(2):30-40.

7. Otrock ZK, Liu C, Grossman BJ. Transfusion related acute lung injury risk mitigation: an update. Vox Sang. 2017;112(8):694-703.

8. Guazzi M, Galiè N. Pulmonary hypertension in left heart disease. Eur Respir Rev. 2012;1;21(126):338-46.

9. Karim A, Arora VK. Applications of ultrasonography in respiratory care. Indian J Chest Dis Allied Sci. 2014;56(1); 27-31.

10. Frassi F, Gargani L, Tesorio P, Raciti M, Mottola G, Picano E, et al. Prognostic value of extravascular lung water assessed with ultrasound lung comets by chest sonography in patients with dyspnea and/or chest pain. J Cardiac Fail. 2007;13:830-5.

11. Nafae R, Eman SR, Mohamad NA, El-Ghamry R and Ragheb AS. Adjuvant role of lung ultrasound in the diagnosis of pneumonia in intensive care unit-patients. Egypt J Chest Dis Tuberc. 2013;62: 281-85. 